\title{
NOTAS EN TORNO A LA ENUNCIACIÓN DE JOSÉ VASCONCELOS EN LA RAZA CÓSMICA ${ }^{1}$
}

\author{
Miguel Enrique Morales ${ }^{2}$ \\ mqmorale@uc.cl \\ Pontificia Universidad Católica de Chile
}

\section{RESUMEN / ABSTRACT}

El presente artículo analiza La raza cósmica (1925) de Vasconcelos, atendiendo a su enunciación, entendida, según Benveniste, como la apropiación subjetiva de la lengua pública. Mi intención es mostrar cómo las tesis grandilocuentes, civilizatorias, racistas y estéticas resumidas en el proyecto cósmico se enmarcan en un contexto nacional y global bien específico. Así, identifico las huellas de seis discursos en la propuesta de Vasconcelos: el de la Revolución mexicana, el de la crisis occidental del periodo entre guerras, el de la reacción ateneísta frente al positivismo, el de la mestizofilia, el del continentalismo estadunidense y el del continentalismo latinoamericano.

PALABRAS CLAVE: enunciación, latinoamericanismo/anti-imperialismo, redención, Revolución mexicana, mestizofilia.

1 Este artículo es una versión, condensada, de un capítulo de mi tesis doctoral relativa al estudio de la construcción de una imagen de México en relación con la presencia política, económica y cultural de Estados Unidos en tres ensayistas mexicanos del siglo XX: Vasconcelos, Paz, Monsiváis. Este estudio ha sido posible gracias al patrocinio de CONICYT, Beca Doctorado Nacional 2013, folio No 21130964. Asimismo, esta investigación se enmarca en el proyecto FONDECYT N ${ }^{\circ} 1160230$.

2 Agradezco al Centro de Investigación y Docencia Económicas (CIDE), México, institución que apoyó la realización de este capítulo de mi tesis con su invitación a pasar una temporada como investigador visitante entre 2014 y 2015. En especial, agradezco al Dr. José Antonio Aguilar Rivera tanto por su patrocinio como por su formación académica e intelectual. Asimismo, agradezco al Dr. Roberto Hozven, tutor de esta tesis, por sus innúmeras correcciones y su formación en el ensayismo hispanoamericano. 
This article analyzes Vasconcelos 'La raza cósmica (1925) and underlines its enunciation: the individual act of appropriating of the public language-according to Benveniste's definition. My goal is demonstrating how his grandiloquent, civilizing, racist and aesthetic thesis-summarized in the cosmic project-belong to a very specific national and global frame. I identify traces of six discourses in Vasconcelos' proposal: the Mexican Revolution, the Western crisis during the inter-war period, the Ateneo de la Juventud's reaction against the positivism, the mestizofilia, the North-American continentalism, and the Latinamerican continentalismo.

KEYWORDS: enunciation, latinamericanism/anti-imperialism, redemption, Mexican Revolution, mestizofilia.

José Vasconcelos es una de las figuras intelectuales más trascendentes del siglo XX hispanoamericano. Digo trascendente porque su excepcionalidad no radica en su sistema filosófico o intelectual, sino en los alcances de su magna obra política y cultural emprendida desde la conducción de la Secretaría de Educación Pública entre 1921 y 1924, así como en su fallida candidatura a la presidencia el año 1929. Estas incursiones públicas constituyen las más destacadas y determinantes de un pensador hispanoamericano durante la centuria pasada, solo comparables a las de Domingo Faustino Sarmiento durante el siglo XIX. En sus incursiones subyacía la convicción "de que su destino vital era ser el guía espiritual del país en esa su época de renovación posrevolucionaria" (Garciadiego 50). No obstante, solo tras su salida de la SEP, Vasconcelos sistematiza su utopía política y cultural con La raza cósmica (1925). En este opúsculo-manifiesto presenta su carta de navegación para la renovación espiritual de México así como de Occidente entero.

Si bien esta empresa de renovación espiritual se ha asociado principalmente a la participación de Vasconcelos dentro de la Revolución mexicana, creo que en la enunciación de La raza cósmica rumorean los ecos de una pluralidad de discursos políticos y culturales no solo nacionales sino también globales. Vasconcelos dialoga y polemiza implícita o explícitamente con esos discursos. Estos explican la proyección universalista y redentorista de la utopía cósmica. Al mismo tiempo, revelan su conciencia de los procesos políticos y culturales por los que atravesaba la sociedad occidental tras el fin de la Gran Guerra. Con el objetivo de entender cómo se gestan algunas de las pretensiones de la utopía vasconceliana, propongo abordar La raza cósmica desde la perspectiva de su enunciación y no de sus enunciados. Cuando digo enunciación, invito a ponderar su ensayo desde la apropiación vasconceliana de la lengua pública y colectiva, tal como lo expresan los procedimientos discursivos 
que trasuntan su actitud y su postura subjetivas frente a sus tesis. Esta ruta de análisis permite develar no solo la manera por la cual Vasconcelos, en su enunciación, se subjetiviza mediante determinadas formas discursivas, sino también el modo en que ciertos procesos históricos y ciertos discursos culturales intervienen y varían de modo objetivo su enunciación. En este sentido, mi hipótesis es que la utopía cósmica está signada por una serie de discursos históricos, políticos, culturales y filosóficos, los cuales intervienen en su enunciación así como esta los transforma. Sin atender a estos discursos y a las modalidades por las que la enunciación vasconceliana los reelabora, no podemos comprender a cabalidad ni las motivaciones y certidumbres subyacentes a la utopía cósmica ni la efectiva proyección histórica y política de su ideal de sociedad.

¿Cuáles son los discursos que atraviesan y determinan la enunciación vasconceliana? Atendiendo a lo que Roberto Hozven (2011) ha denominado el circuito de interlocución específico de la enunciación, percibo en la producción de los enunciados de Vasconcelos la interacción de, al menos, seis discursos. Estos discursos -o los procesos históricos que los generan- se solapan y determinan mutuamente en La raza cósmica. No obstante, dichos discursos no corresponden a un único tipo de imaginario o a un solo proceso histórico. Por este motivo, propongo distinguir tres circuitos de interlocución en la enunciación de Vasconcelos: primero, el histórico; segundo, el ideológico-científico; tercero, el ideológico-político. En el nivel histórico, el circuito de interlocución está interferido por dos coyunturas: una global y otra nacional. La global: es la década posterior a la entonces considerada Gran Guerra (la primera Guerra Mundial); la nacional: es el comienzo de la fase "institucionalizada" de la Revolución mexicana. En el nivel científico-ideológico, el circuito de interlocución vasconceliano está dominado por las ideas del positivismo en torno a la superioridad de "la raza anglosajona". En el nivel ideológico-político, el circuito de interlocución está interferido por tres discursos: el nacionalista, con énfasis en la mestizofilia; el continentalista norteamericano (la Misión y el Destino Manifiesto) y el continentalista latinoamericanista. Vasconcelos, como veremos, enuncia su proyecto cósmico en clara interacción con estos discursos, ya sea mediante el diálogo fecundo (dentro de o con ellos) o en abierta polémica (contra ellos). 


\section{LA ENUNCIACIÓN COMO CONCEPTO}

Según Emile Benveniste, en el plano de la producción del discurso debemos distinguir dos instancias: el enunciado y la enunciación. Si el enunciado es "una serie de frases, identificadas sin referencia a una determinada aparición de esas frases", la enunciación es "un acto en cuyo transcurso esas frases se actualizan, asumidas por un locutor particular, en circunstancias espaciales y temporales precisas" (Todorov, "Enunciación" 364). La actualización de las frases es, a la larga, la "producción" de dichos enunciados. Roberto Hozven agrega que la enunciación da cuenta "del acto de hablar (o de escribir) como un proceso lingüístico que significa a un sujeto de modo subjetivo (en las formas discursivas por las que asume su subjetividad) y objetivo (en el discurso histórico por el que ideologiza la lengua)" (166-67). Así, todo enunciado, oral o escrito, es posible gracias a la enunciación de su productor: "Antes de la enunciación, la lengua no es más que la posibilidad de la lengua" (Benveniste, Problemas II 84). A través de la enunciación, el sujeto asume su "subjetividad lingüística" - como en el "yo vengo a hablar por vuestra boca muerta" nerudiano. Asimismo, la enunciación "objetiva" al sujeto al situarlo dentro del espacio temporal y espacial desde el que habla -el espacio del "orden del discurso" regido por el poder (Michael Foucault) o por el de sus "formas culturales" (Clifford Geertz)-

Los circuitos de interlocución especificados por Hozven en el concepto de enunciación extienden la noción clásica de Benveniste a los procesos de producción discursiva susceptibles de dar cuenta de las huellas ideológicas ínsitas en la enunciación. Expliquemos brevemente: desde la perspectiva lingüística clásica, el sujeto se constituye como tal a través del lenguaje: "Es en y por el lenguaje como el hombre se constituye como sujeto, porque solo el lenguaje funda en realidad, en $s u$ realidad que es la del ser, el concepto de 'ego"” (Benveniste, Problemas I 180, énfasis en el original). Esta constitución de la subjetividad se da, en el plano del discurso, a través de "un proceso de apropiación" de la lengua (Problemas II 84). Dicha apropiación de la lengua es la enunciación, definida como "este poner a funcionar la lengua por un acto individual de utilización", consistente en "el acto mismo de producir un enunciado y no el texto del enunciado" (83). La enunciación, por tanto, destaca el proceso que interviene ese producto llamado enunciado. Así, la atención al concepto de enunciación permite responder a la pregunta de "quién habla" en el discurso: el acto de apropiación "introduce al que habla en su habla" (85). 
En un segundo nivel, la enunciación es también un proceso de "objetivación" del locutor. Si en el plano de la apropiación del aparato formal de la lengua el locutor se constituye como sujeto, al utilizar una lengua que es de dominio colectivo el sujeto es "objetivado", a su vez, por las huellas ideológicas presentes en todo discurso, especialmente en el ámbito de las frases de la lengua. En este sentido, "Todo acto de habla -todo acto de enunciacióntroquela un discurso subjetivo y una ideología social a través de un proceso lingüístico que significa al hablante de modo heterogéneo, multivalente y contradictorio" (Hozven 167). El locutor, en la enunciación, es "significado" por las marcas históricas e ideológicas orquestadas por y en los signos de la lengua, cuyo dominio no es privado, sino colectivo: "la lengua no es un elemento neutro, sino que está impregnada de ideas, acciones y juicios legados por el pasado; divide lo real de una manera concreta y nos transmite imperceptiblemente una visión de mundo" (Todorov, El miedo 84). En una advertencia barthesiana, el segundo nivel de la enunciación o, mejor dicho, esta "otra" cara del proceso de enunciación destacada por Hozven, apunta a escuchar aquellas voces detrás del texto que no necesariamente corresponden a la del locutor formal del enunciado, sino más bien a las de la cultura y los distintos códigos semióticos que historizan todo discurso. En la enunciación, el locutor se "objetiviza", al "enmarcarse" en un espacio y un tiempo preciso. Su pista podemos seguirla mediante las marcas semióticas que dan cuenta de ese marco o, parafraseando la nomenclatura de Edward Said, de ese "mundo" que murmura en el texto.

Este "mundo" es plausible de asir mediante los circuitos de interlocución ínsitos en la enunciación: "Hablar o escribir implica", para el sujeto, "asumir su discurso como miembro (incluido o excluido) de un grupo que asigna funciones, lugar y trascendencia (aunque esta pueda ser nula) al acto de habla emitido" (Hozven 167). Así, por ejemplo, cuando José Vasconcelos enuncia el lema del escudo de la UNAM, "Por mi raza hablará el espíritu", proyecta, por un lado, un programa de fusión de la nacionalidad mexicana con "las necesidades del espíritu, cuyo predominio es cada día mayor en la vida humana" (Vasconcelos, Discursos 15); y, por otro lado, dialoga y polemiza ideológicamente con el discurso racial norteamericano, el cual proclamó, durante el siglo XIX, "la superioridad de la raza anglosajona" (Merk 125-26) frente a los mestizos mexicanos. Considerados retrógrados por sus conductas incivilizadas -de acuerdo al estándar norteamericano (cf. Merk 34)-, los mestizos mexicanos representaban una amenaza para la pretendida pureza de la raza anglosajona: "a unión of Americans and Mexicans would be an 
evil amalgation, which would be deplorable in its results" (159). Al escribir "raza" en el escudo de la UNAM, Vasconcelos dialoga con el imaginario del discurso racial norteamericano. Es esta una de las marcas de la enunciación que se asoman en uno de sus circuitos de interlocución.

\section{II.ELCIRCUITODEINTERLOCUCIÓNHISTÓRICO:LAREVOLUCIÓN MEXICANA Y LA CRISIS DEL DISCURSO OCCIDENTAL POST GRAN GUERRA}

¿Cuál es, entonces, la enunciación de Vasconcelos en La raza cósmica? Es decir, ¿cuáles son las "circunstancias espaciales y temporales precisas" (Todorov) en que o por las que Vasconcelos asume lo que enuncia, lo que escribe? ¿De qué modo significa, subjetivamente, lo que dice? ¿De qué modo asume, en su discurso, las ideologías que lo historizan (Hozven), y cuáles son estas?

Partamos por dar cuenta de un primer circuito de interlocución presente en la enunciación vasconceliana: el histórico. Vasconcelos participa de modo conspicuo en la coyuntura de la Revolución mexicana (1910-1952) en el primer lustro (1921-1925) de la fase "institucional" de esta (1921-1952) ${ }^{3}$, a través de su función de Secretario de Educación Pública. Desde aquí inicia una "cruzada de educación pública" (Vasconcelos, Discursos 13), con el objetivo de preparar al pueblo mexicano para la misión de alcanzar aquella fase de la Historia (con mayúscula) donde se "fundirán todos los pueblos" (La raza 14): "Esteta en el poder, Vasconcelos puso en funciones desde el principio su fantasía de la raza cósmica" (Domínguez Michael 91). La importancia de este lugar particular de enunciación en la sociedad mexicana de la década del veinte se visibiliza en la concepción -en su doble sentido de entender y de fecundar- de esta empresa educativa. La Revolución mexicana aparece textualmente en el último párrafo de La raza cósmica, cuando comenta la utilización de un edificio público para "plasmar", alegóricamente, esta idea:

Para expresar todas estas ideas que hoy procuro exponer en rápida síntesis, hace algunos años, cuando todavía no se hallaban bien definidas, procuré darles signos en el nuevo Palacio de la Educación Pública de México [...]. En los tableros de los cuatro ángulos del patio 
anterior hice labrar alegorías de España, de México, Grecia y la India, las cuatro civilizaciones particulares que más tienen que contribuir a la formación de la América Latina [...]. Finalmente, en el centro debía erigirse un monumento que en alguna forma simbolizara la ley de los tres estados: el material, el intelectual y el estético. Todo para indicar que, mediante el ejercicio de la triple ley, llegaremos en América, antes que en parte alguna del globo, a la creación de una raza hecha con el tesoro de todas las anteriores, la raza final, la raza cósmica (La raza 35).

Este fragmento revela una huella textual del "espacio temporal y espacial preciso" de la enunciación de Vasconcelos: el circuito de interlocución histórico de la Revolución mexicana donde asume su subjetividad y, al mismo tiempo, ideologiza "la lengua", el discurso del que se apropia para enunciar ${ }^{4}$. Por tanto, sin la coyuntura de la Revolución, es difícil -si no imposible- imaginar un escenario en que Vasconcelos hubiera podido traducir sus ideas personales como principios de acción colectiva de una nación.

Además de la coyuntura nacional, La raza cósmica está situada dentro de una segunda circunstancia histórica clave: la crisis de la civilización occidental tras la entonces Gran Guerra. "Vasconcelos escribía en la inmediatez de un parteaguas histórico: el fin de la Gran Guerra. El mundo estaba aún sacudido por ese acontecimiento. Eran años de dudas y confusión" (Aguilar Rivera 150). La confusión de la sociedad durante esta época se tradujo en una crisis de la visión de mundo construida por la civilización occidental decimonónica:

[L]a primera guerra mundial [...] marcó el derrumbe de la civilización (occidental) del siglo XIX. Esa civilización era capitalista desde el punto de vista económico, liberal en su estructura jurídica y constitucional, burguesa por la imagen de su clase hegemónica característica y brillante por los adelantos alcanzados en el ámbito de la ciencia, el conocimiento y la educación, así como del progreso material y moral. Además, estaba profundamente convencida de la posición central

4 De hecho, este párrafo final de La raza cósmica retoma un pasaje del discurso pronunciado el año 1922 durante "El acto de inauguración del nuevo edificio de la SEP": "[en] las figuras que decoran los tableros del patio nuevo [...] Grecia [...] España [...] La figura azteca [...] [y] Buda [India] [...] [representan] una sugestión de que en esta tierra y en esta estirpe indoibérica se han de juntar el Oriente y el Occidente, el Norte y el Sur, no para chocar y destruirse, sino para fundirse y confundirse en una nueva cultura amorosa y sintética" (Vasconcelos, Discursos 39). 
de Europa, cuna de las revoluciones científica, artística, política e industrial [...] (Hobsbawm 16).

La crisis se refleja, sobre todo, en el cuestionamiento a la centralidad de Europa como referente en las dimensiones cultural, política y moral. Y en este cuestionamiento, un aspecto clave de la lucha por el liderazgo "espiritual" del mundo se centra en la discusión de "la cuestión racial" (Aguilar Rivera 150).

Vasconcelos sabía de esta crisis. También de la vacante en el liderazgo "espiritual" del mundo. Así, mediante su proclama en torno a la superioridad de la "raza latina", el educador mexicano sitúa a los latinoamericanos como los llamados a asumir el rol de vanguardia espiritual del mundo: "Tenemos, pues, en el continente todos los elementos de la nueva Humanidad" (La raza 34). ¿Por qué son los latinoamericanos la próxima vanguardia espiritual del mundo? Para responder esta pregunta, y situarla en el contexto de la crisis de la civilización occidental, debemos atender a la reformulación vasconceliana de la teoría comtiana de las tres etapas de la humanidad. Según esta, la historia se desarrolla en tres etapas: la teológica o ficticia, la metafísica o abstracta y la científica o positiva. Para Vasconcelos, en cambio, la humanidad está compuesta por otros tres estadios progresivos: "el material o guerrero, el intelectual o político, y el espiritual o estético" (La raza 23). En el primer estadio, los pueblos están sometidos al absoluto "imperio de la necesidad". En el segundo, la humanidad está dominada por "la inflexible norma de la razón". La razón representa un avance respecto al primer estadio de caos y violencia; no obstante, también implica un alto costo a la libertad individual, pues instala la coerción opresora y la razón utilitaria: "en nombre de la política se restringen libertades interiores y exteriores; en nombre de la religión, que debiera ser inspiración sublime, se imponen dogmas y tiranías; pero cada caso se justifica con el dictado de la razón, reconocido como supremo de los asuntos humanos" (23-4). La razón no solo constriñe las libertades "políticas" del hombre: para Vasconcelos, también restringe las acciones guiadas por el gusto libre y desinteresado, al erigir el cálculo utilitario como norma de elección y acción individual.

Frente a esto, Vasconcelos anuncia, en 1925, la llegada de un tercer periodo, el cual sucederá a este estadio cuya crisis es desencadenada por la Gran Guerra: "La decadencia de las costumbres, la pérdida de las libertades públicas y la ignorancia general, causan el efecto de paralizar la energía de toda una raza, en determinadas épocas" (La raza 9-10). En un circuito intelectual sacudido por la publicación de La decadencia de occidente (1918, 
1923) de Oswald Spengler, la palabra "decadencia" es una alusión clara a dicha crisis cultural occidental. El tercer periodo de la historia, el espiritual o estético, superará dicha crisis mediante la liberación de lo más dinámico del hombre: su creatividad. A su vez, este "sentimiento creador" se inspirará "en la belleza que convence" (24). El segundo estadio de la humanidad está moribundo: la razón, la coerción, la sociedad fundada en el principio burgués y liberal ya dio sus frutos. Europa sembró sus semillas, y también cosechó su autodestrucción. Sin embargo, el fruto de sus semillas en América persiste con el plan original del universalismo europeo: Estados Unidos y América Latina continúan el afán de reincorporar el mundo a una unidad "preuniversal" (5-6).

Para Vasconcelos, el asunto es dirimir cuál de los dos orbes culturales de América concretará este plan "trascendental" de la civilización europea: los anglosajones o los latinoamericanos. No duda en la respuesta: el anglosajón, en tanto extensión del hombre blanco, "después de organizarse en Europa, se ha convertido en invasor del mundo, y se ha creído llamado a predominar lo mismo que lo creyeron las razas anteriores, cada una en la época de su poderío" (La raza 5). Por tanto, el norteamericano es el último vestigio de la civilización "dominadora", de la cultura propia del estadio coercitivo del mundo. Ellos no pueden ofrecer una entrada al tercer estadio de la humanidad, porque persisten en la lógica de dominación propia del imperialismo europeo. No obstante, con su avance tecnológico, cumplirán un rol crucial en la "unificación" del mundo: servir "de puente": "El blanco ha puesto al mundo en situación de que todos los tipos y todas las culturas puedan fundirse" (5). Gracias a los avances en transporte y telecomunicaciones acometidos por los anglosajones, la humanidad tendrá una conexión para llegar a su tercera etapa, la estética o espiritual. Y en esta etapa, no son sino los latinos quienes liderarán el proceso de unión universal. ¿A qué se debe el rol central de los latinoamericanos? La respuesta está en la historia: ellos han estado abiertos a la mezcla con otras estirpes, al mestizaje, esto es, a la "mezcla" entre razas diferentes.

La raza cósmica es un proyecto que "aspira a englobar y expresar todo lo humano" (La raza 15). Como explica Diego von Vacano, el proyecto estético de Vasconcelos -base de este tercer estadio de la humanidad- se articula sobre un criterio filosófico de "armonía" entre elementos diferentes. Esto, en el dominio político-cultural, se traduce en este proyecto de supuesta integración universalista mediante el mestizaje de lo mejor de las distintas razas: "By combining miscegenation with the ethnocultural mixing of ideas of beauty, Vasconcelos provides a truly cosmopolitan, global vision of a 
movement toward a universalist sense of beauty produced not by abstract reason, as in Kant, but by real, biological, historical, and social processes in the progress of "miscegenation"' (133).

Ante la crisis de la civilización occidental, el proyecto cósmico ofrece, según Vasconcelos, una alternativa más inclusiva (pero no del todo pluralista) que el exclusivismo norteamericano o los movimientos nacionalistas que se gestaban en Europa. La crisis valórica tras la Gran Guerra es una de las razones por las que Vasconcelos se obsesiona en figurar su utopía como universal. El "aquí" espacio-temporal de la enunciación vasconceliana es, simultáneamente, un aquí impulsado por la coyuntura nacional así como en la crisis occidental. A esta última le ofreció una respuesta a partir de la realidad nacional que él estaba moldeando. "La Revolución Mexicana [...] mostraba la vitalidad de determinados procesos sociales frente a lo 'decadente' del orden estructurado hasta la Primera guerra” (Funes 50). ¿Ingenuo? ¿Megalómano? Puede que ambas. Sin embargo, es esto mismo lo que le da su carácter de pensador mexicano universal del siglo XX (Aguilar Rivera 151).

\section{EL CIRCUITO DE INTERLOCUCIÓN IDEOLÓGICO-CIENTÍFICO: POSITIVISMO PORFIRISTA, EUGENESIA Y LA REACCIÓN ATENEÍSTA}

El segundo circuito de interlocución de la enunciación vasconceliana es el ideológico-científico del positivismo en México. El porfirismo, guiado por sus intelectuales conocidos como los "científicos", busca alcanzar el desarrollo del capitalismo en México (Córdova 13). En pos de este objetivo, el porfiriato alienta la "penetración económica de las potencias imperialistas" (17). Gran parte de dicha política porfirista es legitimada ideológicamente por los positivistas mexicanos, quienes implantan la "idea del atraso material del país" (17). Este retraso es razón suficiente para alentar y justificar la penetración económica, así como para establecer el sistema de privilegios para las clases dominantes y los inversores extranjeros que desencadenaría en la dictadura de Porfirio Díaz: un "régimen en el cual el poder político se emplea directamente para proteger y promover el capitalismo [...] usando la violencia ilimitada cuando alguno de los sectores sociales sometidos pretendía oponerse al sistema de privilegio" (17-8). Con una mescolanza de comtismo, spencerianismo y una cuota de darwinismo, los positivistas profieren su diagnóstico del país: 
Los escritores positivistas, que prepararon ideológicamente el advenimiento de la dictadura, bajo las consignas comtianas de "orden y progreso", facilitaron la labor de aquella, al proporcionarle una justificación histórica y filosófica de carácter naturalistas, de acuerdo con la cual lo que se hacía, no solo respondía a necesidades inmediatas de la sociedad, sino que lo imponía la propia naturaleza, por encima de lo que los hombres pensaran o desearan. En la naturaleza los seres son desiguales por necesidad y los más aptos en la lucha por la vida se imponen indefectiblemente a los más débiles. Del mismo modo, en la sociedad los más aptos son llamados a triunfar sobre los más débiles, con la particularidad de que los más aptos son precisamente los poseedores de la riqueza; la capacidad y aun la responsabilidad social se miden por la riqueza misma (18).

El diagnóstico positivista de la sociedad mexicana del último tercio del siglo XIX alienta un proceso de "modernización" sobre la creencia del atraso "material" y "moral" del país. Este proceso de modernización tuvo dos grandes ejes sociales: el desarrollo del capitalismo y, con este, la industrialización del país. La Revolución mexicana, como sabemos, es un levantamiento contra el sistema de privilegios y la dictadura porfiristas cimentadas en los ideales "positivos".

El desarrollo del capitalismo y la industrialización del país que persiguen los positivistas mexicanos tiene dos modelos claros: Estados Unidos, a nivel económico-social, y Europa, en el nivel cultural: "Los positivistas [del porfirismo] se habían propuesto norteamericanizarse" (Villegas 56). Esta obsesión, justificada por los positivistas en su lectura de la raza anglosajona como vanguardia económico-social frente al retraso de la latinoamericana, implica un correlato ideológico-cultural concreto: la dependencia cultural. La norteamericanización opera tanto a nivel de proyecto modernizador como en el espacio del discurso de autocomprensión de las naciones y las culturas latinoamericanas: estas se cartografían a sí mismas como sociedades inferiores por su componente étnico. Algunos intelectuales emblemas de esta postura son los argentinos Domingo Faustino Sarmiento ${ }^{5}$ (Conflicto y armonías de

\footnotetext{
Domingo Faustino Sarmiento es tajante tanto en su admiración por Estados Unidos como en su figuración de América Latina como sociedad inferior: "Lleguemos a enderezar las vías tortuosas en que la civilización europea vino a extraviarse en las soledades de esta América [...] La América del Sur se queda atrás y perderá su misión providencial de sucursal de la civilización moderna. No detengamos a Estados Unidos en su marcha [...] Alcancemos
} 
las razas de América, 1883) y Carlos Octavio Bunge (Nuestra América, 1903), además del mexicano Francisco Bulnes (El porvenir de las naciones latinoamericanas, 1899). En México, esta comprensión autodenigratoria refuerza la dependencia cultural con los modelos norteamericanos y europeos. De aquí que Basave catalogue esta época como "la era de la xenofilia institucionalizada, de la obsesión por la inmigración europea, del desprecio social por el 'lastre indígena' y de la voluntad política de destruirlo por la fuerza de las armas" (37).

Vasconcelos no desconoce esta "episteme eugenésica" (Rojas 597). De hecho, es contra la valoración de la cultura y la población "híbrida" 6 desprendida de esta episteme eugenésica que enuncia, como respuesta, sus tesis del mestizaje y de la superioridad de los latinoamericanos.

Los británicos predican la selección natural, con la consecuencia tácita de que el reino del mundo corresponde por derecho natural y divino al dolicocéfalo de las Islas y sus descendientes. Pero esta ciencia que llegó a invadirnos junto con los artefactos del comercio conquistador, se combate como se combate todo imperialismo, poniéndole enfrente una ciencia superior, una civilización más amplia y vigorosa (Vasconcelos, La raza 29).

El discurso de la superioridad étnica y cultural de la raza anglosajona implica un peligro para Latinoamérica, en cuanto constituye un pilar del expansionismo norteamericano. Por lo mismo, es todavía más peligroso que sean los propios "latinos" los que reproduzcan este discurso. Para Vasconcelos, esta episteme, al convencer a los latinoamericanos de su "inferioridad" frente a la nación anglosajona, ha facilitado lo que Edward Said denomina "pacificación ideológica"

a los Estados Unidos" (cit. en Rojas 607). Según Rafael Rojas, la aceptación de la episteme eugenésica como comprensión de las sociedades latinoamericanas lleva a algunos de estos intelectuales al extremo de reproducir "los argumentos de Edmund Demoulins en aquel ensayo que asustara a los latinófilos inseguros: ¿A qué se debe la superioridad de los anglosajones?" (598).

Escribe Spencer, a propósito de las sociedades "híbridas", o, como dirían MolinaEnríquez y Vasconcelos, mestizas como la mexicana: "Es una unidad cuya naturaleza no ha sido moldeada por ningún tipo social, y por ende no puede, con otros de su misma naturaleza, evolucionar en ningún tipo social. El México moderno y las repúblicas sudamericanas, con sus revoluciones perpetuas, nos muestran el resultado [...] las sociedades híbridas son imperfectamente organizables" (cit. en Brading 178). 
de todo imperialismo (42) -en este caso, del imperialismo norteamericano, mediante la aceptación de su potencia, de su superioridad cultural-.

La seducción creada por este discurso lleva a muchos latinoamericanos a considerar de modo negativo y despectivo su condición de "americanos" del orbe latino. Dicha visión autodenigratoria fue observada sagazmente por Alfonso Reyes en sus "Notas sobre la inteligencia americana" (1936). Según Reyes, cuatro eran las fatalidades concéntricas en las que se sentía presa la generación latinoamericana que lo precede (la generación previa a los ateneístas): "ser humanos" (nacer), "haber llegado tarde a un mundo viejo" ("ser modernos"), "ser americanos" y, por último, "ser latinos" (90). La última fatalidad traduce una aceptación de la episteme eugenésica: "Y ya que se era americano, otro hándicap en la carrera de la vida era el ser latino o, en suma, de formación cultural latina. Era la época del A quoi tient la supériorité des Anglo-Saxons? Era la época de la sumisión al presente estado de las cosas, sin esperanzas de cambio definitivo ni fe en la redención" (90).

Este discurso "ideológico-científico" circulante en las "circunstancias espaciales y temporales precisas" (Todorov) de la enunciación vasconceliana es, probablemente, la más clara de las "ideologías" que "historizan" (Hozven) al Vasconcelos de La raza cósmica. De hecho, la prominencia de este discurso en la autocomprensión de la identidad latinoamericana, así como en la explicación del imperialismo norteamericano, conlleva a Vasconcelos a enunciar un relato contrastante: la tesis de la superioridad de la raza latina ${ }^{7}$ : "La doctrina de formación sociológica, de formación biológica que en estas páginas enunciamos, no es un simple esfuerzo ideológico para levantar el ánimo de una raza deprimida, ofreciéndole una tesis que contradice la doctrina con que habían querido condenarla sus rivales" (La raza 31). Más que un esfuerzo "para levantar el ánimo", Vasconcelos busca invertir la comprensión de los latinoamericanos sobre sí mismos, como un modo de superar -en palabras de Reyes- aquella "fatalidad concéntrica".

Gracias a la brillante pesquisa genealógico-histórica que Rafael Rojas acomete de las "retóricas de la raza", podemos informarnos del modo en que este discurso de la "inferioridad latina" constituyó uno de los dos polos transitados por los hispanoamericanos en el campo ideológico tras la Guerra estadounidense-española de 1898. Rojas también nos informa que las ideas de la "superioridad latina" frente al mundo materialista sajón -argumento troncal de Vasconcelos-, se inician no con Rodó, como se ha creído, sino con el hispanófilo Agustín Aragón (611). 
Ahora bien, son necesarias dos aclaraciones respecto a la relación de Vasconcelos con este circuito de interlocución ideológico-científico. Primero: epistemológicamente, este discurso "eugenésico" que ideologiza e historiza la enunciación de Vasconcelos no es ni superado ni suprimido en La raza cósmica. Me explico: Vasconcelos rechaza las tesis acerca de la superioridad anglosajona, mas no abjura de la episteme eugenésica como explicación de la historia y de la sociedad. Como señala Rafael Rojas, la episteme eugenésica está signada por un “enfrentamiento binario de lo 'latino' contra lo 'sajón"”; este enfrentamiento "involucra entonces, a partir de la identidad étnica, otros enunciados psicológicos, religiosos, económicos y antropológicos que, en suma, conforman un orden moral cívico" (599). En este "razonamiento" eugenésico, la nota característica es la lucha de "diversos imaginarios cívicos, diversas representaciones morales de la ciudadanía, que se perciben, a su vez, como desprendimientos de ciertas raíces étnicas" (599). Vasconcelos enuncia desde el interior de esta episteme eugenésica. El grueso de su doctrina de la raza cósmica, en cuanto respuesta a la tesis de la superioridad anglosajona, descansa en los atributos "simbólicos" que los latinoamericanos, por el solo hecho de ser latinos, poseen.

No obstante, hay una pequeña diferencia con el discurso eugenésico tradicional: el giro "cultural" en la explicación eugenésica de la sociedad. Para Vasconcelos, si algo distinguirá al proceso de constitución de la raza cósmica, es la prevalencia de un nuevo tipo de eugenesia, ya no regida por la "selección" o "evolución" biológica, sino por las "leyes de la emoción, la belleza y la alegría" (La raza 25). La "eugénica científica" propia de la episteme evolucionista es sustituida por una "eugénica misteriosa del gusto estético" (26). Por tanto, más allá de las discrepancias en torno a cuál raza es superior o inferior, Vasconcelos enuncia desde coordenadas similares a las de sus "adversarios" anglosajones y a sus predecesores positivistas. Solo que allí donde estos fijan su mirada en el aspecto biológico, el educador mexicano observa lo "espiritual", los aspectos simbólicos del ser.

El segundo aspecto que debemos precisar acerca de este circuito de interlocución ideológico-científico es el de la data de la reacción contra el positivismo en México. Vasconcelos no es el fundador de esta reacción. Esto no quita, sin duda, que su nombre sea el más trascendente a nivel político. La crítica al positivismo es anterior incluso al estallido de la Revolución: junto a Reyes, Vasconcelos es parte de un amplio grupo de jóvenes intelectuales que reaccionan, en el plano cultural, contra el positivismo: el Ateneo de la Juventud. Constituido formalmente el 28 de octubre de 1909 (Domínguez 
Michael 65), el Ateneo inicia sus reuniones el año 1906 en torno a la publicación de la revista Savia Moderna. Entre sus integrantes destacan los nombres de Antonio Caso, Pedro Henríquez Ureña, Diego Rivera y Martín Luis Guzmán $(65,67)$. Se ha visto en el Ateneo un presagio, en el plano cultural, de la Revolución mexicana: "el Ateneo vivió entre luchas y fue, en el orden de la inteligencia pura, el preludio de la gigantesca transformación que se iniciaba en México" (Henríquez Ureña 275). Entre estas luchas, los ateneístas inician, en el nivel cultural, la crítica a los postulados científicos adoptados por el porfirismo. Abelardo Villegas ha resumido estos postulados como el "mito [...] de la unanimidad en torno a las verdades de la ciencia y el de la guía científica de la política" (13).

Los ateneístas también cuestionan los alcances de este "mito" a nivel político. Frente al enclaustramiento, la dependencia y el aislamiento cultural de México durante el porfirismo, ellos "[e]xpresan la modernidad entendida como el registro de la ciencia, la apertura a vías espirituales, la insistencia en el conocimiento de otras culturas; condenan la carencia de valores humanistas o cristianos y la rigidez educativa al margen de "preocupaciones filosóficas" (Monsiváis 32). Para los ateneístas, el positivismo en México "es una ilustración estéril $[\ldots]$ cuya dependencia de las doctrinas anglosajonas era un obstáculo para la autonomía cultural" (Brading 191). Esta reacción es "el gran adelanto de la actitud liberal y laica" (Monsiváis 34) que, en 1910, personificará, en el escenario político, Francisco I. Madero (del cual Vasconcelos es uno de sus más cercanos intelectuales). Frente al frío mundo de la ciencia -tierra firme y paraíso de los positivistas mexicanos-, del "atenerse a lo dado y no salir jamás de lo dado" - lo que se traduce en la "aversión a la metafísica" (Ferrater Mora 336)-, los ateneístas enarbolan el humanismo, el afán de saber, la fe en la educación. Esta última entendida como "instrumento para la formación de un hombre nuevo [...] Ellos, como educadores, intentaron formar la mentalidad del México revolucionario más allá de la defensa del jacobinismo [de las facciones armadas], con el cual no tenían ningún punto de contacto" (Monsiváis 45).

Si el Ateneo es el preludio cultural a la revolución social, es importante situar con exactitud el rol y la resonancia del Ateneo en los circuitos de interlocución histórico (Revolución) e ideológico-científico (positivismo y darwinismo) de Vasconcelos. El Ateneo es el germen de la crítica a los presupuestos del positivismo mexicano, sobre todo respecto a la fe ciega en la ciencia, al diagnóstico fatalista de México como país atrasado y a la autodenigración simbólico-cultural. No obstante, los integrantes del Ateneo, 
en la fase armada de la Revolución (1910-1920), no juegan rol alguno. Con excepción de Vasconcelos y Martín Luis Guzmán, "la elite cultural mexicana, representada por el Ateneo de la Juventud, tendió a descartar la Revolución, pues vio en ella un descenso a la barbarie, un incoherente conflicto civil con el poder" (Brading 170). "La Revolución significó la diáspora para los ateneístas" (Domínguez Michael 67). Enrique Krauze es aun más tajante en su fotografía a los ateneístas durante la Revolución:

De una u otra forma, todo el Ateneo se exilia. Unos lamentan el estallido revolucionario; otros pocos, Vasconcelos entre ellos, lo celebran o cuando menos lo admiten como un cataclismo natural y necesario, "oleada devastadora y fertilizante". Pero ninguno de estos intelectuales, aun viviendo en el torrente revolucionario, posee un horizonte social o nacional (79).

Si modernos y cosmopolitas frente al retrógrado positivismo de los "científicos", los ateneístas son ciegos y sordos ante la dimensión social de la realidad del país: "Los ateneístas no intentaban siquiera conocerla. Vivían en Grecia, no en México" (79). Solo Vasconcelos sale librado de este diagnóstico, pues al menos comprendió "la naturaleza política del conflicto: la lucha por la libertad y la democracia" (80). No obstante, no le alcanzó para entender la naturaleza social y material del conflicto. Por tanto, si el Ateneo juega un rol central en la Revolución mexicana -afirmación cuestionable, como acabamos de ver-, este es encarnado por la figura de Vasconcelos: él es el único "revolucionario" de primera hora, cuando apoya denodadamente a Madero ${ }^{8}$.

El Ateneo se "fundirá" con la Revolución recién en los años veinte, gracias, precisamente, a la labor educativa de Vasconcelos. Si algo acomete el emisario del mestizaje durante sus años en la SEP, es llevar a acción varias

8 El rol social de los ateneístas durante este periodo es objeto de debate. Por ejemplo, en 1912 fundan la Universidad Popular Mexicana. Esto contradeciría la tesis de Krauze. Sin embargo, es importante señalar que en este artículo lo que se analiza es -para hacer la distinción- "el discurso del discurso" de Vasconcelos y otros ateneístas, y no el "discurso de la acción", sus obras públicas. A nivel de "discurso del discurso", Vasconcelos y otros ateneístas no comprendían o bien vieron con temor y recelo el estallido social de la Revolución. De allí que Krauze afirme que vivían en Grecia, en un mundo idealizado. (Debo la distinción "discurso del discurso" y "discurso de la acción" para este objeto de estudio a Adolfo Castañón, quien me hizo ver dicha diferencia para evitar "afirmaciones" objetables desde otro nivel de análisis, como el histórico.) 
de las premisas de los ateneístas: la educación como medio de mejoramiento social, el ideal clasicista, la difusión de los libros, la contemplación de las bellas artes, entre otros aspectos clave de su cruzada educativa. Un ejemplo: el desarrollo del muralismo. "Claude Fell advierte que el encuentro entre los muralistas y Vasconcelos fue un desarrollo inesperado pero lógico de los anhelos del Ateneo de la Juventud que, truncados por la Revolución, vuelven a encontrarse durante un breve e intenso tiempo" (Domínguez Michael 92). La labor educativa de Vasconcelos, eje de su aporte a la Revolución mexicana, está profundamente enlazada con la reacción contra el positivismo mexicano emprendida por los ateneístas.

Aunque el positivismo como sistema filosófico estaba en retirada hacia los años veinte, los resabios sociales del evolucionismo spenceriano y del darwinismo no se apagaban: en el mundo de entreguerras, "[1]a lucha era por establecer la supremacía de una raza sobre las demás” (Aguilar Rivera 150). Pero antes que revivir el darwinismo social -como afirma Aguilar Rivera-, Vasconcelos quiso embalsamarlo en un escenario definitivo donde las luchas se acabarían con el triunfo integrador de los "estéticamente" más aptos. Esta fue la pretensión tras su versión de la eugenesia social y de la integración de las distintas razas. Este circuito de interlocución es, qué duda cabe, uno de los más determinantes en la enunciación de Vasconcelos.

\section{EL CIRCUITO DE INTERLOCUCIÓN IDEOLÓGICO-POLÍTICO: LA MESTIZOFILIA NACIONALISTA Y LOS CONTINENTALISMOS AMERICANOS}

El tercer circuito de interlocución de la enunciación vasconceliana es el ideológico-político. Aquí identifico tres huellas discursivas: la mestizofilia nacionalista, el continentalismo norteamericano y el continentalismo hispano/ latinoamericano. Califico de "ideológico-político" este circuito de interlocución por dos razones: primero, porque Vasconcelos asume que es en el plano de las ideas donde está en juego la comprensión que los latinoamericanos tendrán de sí mismos - "la guerra de los discursos" dirá Rafael Rojas a propósito de las "retóricas de la raza" revisadas antes-. Segundo, porque una vez lograda una comprensión optimistas de sí mismos, los latinoamericanos podrán proponer un proyecto político para el hemisferio occidental -como lo era, en la mente de Vasconcelos, la utopía de la raza cósmica. 
El primer discurso -en orden y en importancia- de este circuito de interlocución de la enunciación de Vasconcelos es el de la mestizofilia. Según Agustín Basave, la mestizofilia se define, "en su más amplia connotación, como la idea de que el fenómeno del mestizaje -es decir, la mezcla de razas y/o culturas- es un hecho deseable" (13). Esta idea es la lanza, el escudo y la armadura de la tesis "cósmica" de Vasconcelos. Sin embargo, es una idea de larga data en México. Vasconcelos no es su precursor. Sí su ejecutor a nivel estatal-cultural durante sus años en la SEP, y su promotor a nivel continental y universal mediante la tesis señalada en La raza cósmica.

En México, la mestizofilia rastreada por Basave presenta dos grandes rasgos: primero, expresa un deseo de "homogeneidad" racial y cultural con el fin de "encontrar comunes denominadores y factores de unidad nacional" (15); segundo, aspira a eliminar las "castas" en un país multiétnico. Este segundo rasgo no es una redundancia del primero: eliminar las castas en el México del siglo XIX implica suprimir el sustrato étnico como factor de ubicación en la pirámide social, cuyo origen está en el sistema colonial y en las Leyes de Indias.

Con estos rasgos esclarecidos, Basave traza una suerte de genealogía de la mestizofilia en México. Aquí, un primer promotor de esta idea es el Dr. José Luis Mora (1794-1850), importante ideólogo liberal de mediados del siglo XIX. Mora, quien en 1836 decretara la "desnacionalización" de los indígenas y el dominio de la población blanca en México, postula en 1849 la primera proclama mestizófila proveniente desde el ala liberal del pensamiento mexicano. Mora ve en la "fusión" de castas un medio para alcanzar el cese de las sublevaciones intestinas padecidas por México (Basave 23-4). El mestizaje, por tanto, es una opción de "paz social". Después de Mora, otro importante pensador que aboga por el mestizaje en México es Francisco Pimentel (18321893). A pesar de su extraño conservadurismo liberal (dedica su obra cumbre a Maximiliano), Pimentel propone el mestizaje por dos motivos: primero, para mejorar la situación social indignante del indio, condenado a la escala más baja de la pirámide social solo por nacer indígena; $y$, segundo, para lograr una homogeneidad cultural (Basave 26). De hecho, Pimentel aboga por el mejoramiento de la situación social del indígena, siempre y cuando vaya acompañado de un "blanqueamiento" cultural, mediante su sometimiento a la misma educación recibida por el blanco, con el objeto confeso de que acepte los patrones culturales y sociales de este último (Basave 27). Después de Pimentel, aparecen en la línea mestizófila dos eminentes mexicanos de fines del siglo XIX: Vicente Riva Palacio (1832-1896) y Justo Sierra (18481912). El primero es el encargado de maridar "mestizaje y mexicanidad", de 
modo que se "otorga al mestizo la [propiedad] exclusiva de la nacionalidad mexicana" (30). El segundo, por su parte, aporta a la idea mestizófila la ecuación mestizo es igual a clase media (35).

Paz social (Mora), mejoramiento social y blanqueamiento cultural (Pimentel), maridaje mestizo-mexicanidad (Riva Palacio), correspondencia mestizo-clase media (Justo Sierra): con distintas tonalidades y énfasis, estos cuatro aspectos de la mestizofilia resuenan en el elogio al mestizaje presente en el discurso cósmico construido por Vasconcelos. Quizá la idea menos clara es la de "paz social": Vasconcelos no se refiere a ella en términos explícitos. No obstante, si trasladamos su idea en torno a la armonía de razas que el mestizaje promueve, podríamos encontrar una difusa $-\mathrm{y}$ poco convincentesimilitud entre la paz para México que el mestizaje representa en la lectura de Mora, y la paz que traería al mundo la armonía de las distintas razas 9 . El mejoramiento social tampoco aparece muy claro en Vasconcelos, pero no porque este ignorara su situación, sino porque si algo caracteriza a su ensayo es la ausencia de referencias a la situación material de los indios y los mestizos. Pareciera que, para él, la condición social ya estuviera mejorada o, lisa y llanamente, no fuera tema. No por nada, Krauze nos advertía que Vasconcelos, el ateneísta más "politizado", no supo leer la realidad social tras la Revolución mexicana en 1910. En la década del veinte ya la conocía bien, pero aun así no la aborda más allá de uno u otro adjetivo aislado en su argumentación. El blanqueamiento cultural, en cambio, es explícito: según Vasconcelos, "El indio no tiene otra puerta hacia el porvenir que la puerta de la cultura moderna, ni otro camino que el camino ya desbrozado de la civilización latina" (La raza 13). El tercer rasgo de la mestizofilia, el maridaje entre mestizaje y mexicanidad, es un punto de partida para su sermón cósmico: México es el país mestizo por excelencia, y, en consecuencia, es el dechado de "la raza cósmica" para Latinoamérica y el resto del mundo. Aun cuando no

9 En una sugerente lectura, Diego von Vacano vincula los pensamientos estéticos de Vasconcelos con los de Nietzsche. En este punto, von Vacano subraya una similitud entre el mexicano y el alemán: la estética como recurso para superar los antagonismos: "Nietzsche finds in the aesthetic a way to resolve the tensions and antagonism that he finds inevitable in other realms of life" (120); "Moving from apparent discord to harmony: this is Vasconcelos's Project in his dealing with all phenomena, including racial ideas" (125). Tal vez se podría ver en este afán de armonía de las distintas razas subyacente en la tesis del mestizaje de Vasconcelos, una extensión estética de esta "paz social" de Mora. No obstante, dicho ejercicio teórico rebasa los límites de una aproximación literaria, histórica y cultural como la que yo acometo en este estudio. 
explicite esta idea en La raza cósmica, el circuito de interlocución histórico que lo atraviesa, con sus referencias al edificio de la SEP y su cruzada educativa, parten de la aceptación de esta premisa. El último rasgo, el de la equivalencia entre mestizaje y clase media, es un supuesto ausente en el texto de La raza cósmica. Pero de modo similar a lo concerniente a la condición social de los indígenas, Vasconcelos no acostumbraba hacer referencias a las situaciones materiales y socioeconómicas ${ }^{10}$.

La mestizofilia de Vasconcelos presenta, no obstante, una gran divergencia con la mestizofilia de los mexicanos antes revisada: la trascendencia de las fronteras del Estado-nación. Todos los mestizófilos señalados son, a su manera, nacionalistas a la usanza decimonónica, es decir, constreñidos a la construcción del Estado-nación. Vasconcelos, en cambio, enarbola un ideal continentalista, primero, y universal después. Es decir, un programa con una marcada "cosmopolitan dimension. That is, it trascends nationalistic boundaries" (von Vacano 116) ${ }^{11}$. La trascendencia de la frontera nacional en la tesis de Vasconcelos está interferida por dos discursos continentalistas: el norteamericano y el latinoamericano. Vasconcelos sabe que el discurso acerca de la superioridad norteamericana en base a las diferencias raciales entre anglosajones y latinos fungió como sustrato científico para el proyecto político del imperialismo norteamericano. Este imperialismo tuvo, durante el siglo XIX, dos pilares: el político, basado en la Doctrina Monroe (1823) y en la propuesta de un panamericanismo (1889); el retórico-cultural, alojado en

10 Quizás es por este motivo que Vasconcelos no hace referencia a los postulados de Andrés Molina Enríquez, el gran mestizófilo de inicios del siglo XX, quien elaboró un brillante análisis socioeconómico de la condición de los mestizos mexicanos en su obra magna, Los grandes problemas nacionales (1909).

11 Existe acuerdo en señalar la tesis cósmica no como nacionalista, sino como continentalista y universal. "Rather than remain a Mexican nationalist, Vasconcelos urged the creation of a common Latin American civilization with a higher purpose" (von Vacano 126). Aunque suscribo esta hipótesis, creo que el antecedente mestizófilo del pensamiento vasconceliano no se puede obviar. Si bien Vasconcelos busca trascender el nacionalismo mexicano en su propuesta, su lectura de la cultura latinoamericana parte de la premisa de corresponder, sinecdóquicamente, a Latinoamérica con el mestizo y la cultura mexicana. Esto queda claro en sus conferencias de 1926 en la Universidad de Chicago, tituladas "The LatinAmerican Basis of Mexican Civilization", y traducidas como La otra raza cósmica: "De esta manera, el mestizo no puede remontarse por entero a sus padres, ya que no es exactamente como ninguno de sus ancestros, y al ser incapaz de vincularse plenamente con el pasado, el mestizo siempre está dirigido al futuro, es un puente hacia el porvenir. Ningún país puede mostrar, como México, todos los signos de esta peculiar psicología mestiza” (120). 
el discurso del Destino Manifiesto y la Misión norteamericana. Si bien estos pilares sostienen el mismo propósito (el imperialismo continental de Estados Unidos), lo cierto es que ambos se desarrollaron en distintos ámbitos. Mientras la Doctrina Monroe actuó en el ámbito político a través, sobre todo, de la diplomacia, el discurso del Destino Manifiesto y la Misión norteamericana se originó y discutió en la opinión pública, para luego ejecutarse a nivel material. En esta ejecución, dos sucesos son claves: primero, la anexión de Texas a mediados de la década del cuarenta del siglo XIX, y, segundo, la Guerra México-Estados Unidos de 1846 a 1848.

A grandes rasgos, el discurso del Destino Manifiesto y la Misión norteamericana fue, en el ámbito geopolítico, una idea "continentalista". Funcionó como argumento para motivar y justificar la expansión estadounidense hacia el sur de su frontera. En su apogeo durante mediados del siglo XIX, esta idea implicó para México la pérdida de casi la mitad de su territorio. Hacia fines del siglo XIX, y a pesar de que la idea de Destino Manifiesto había caducado, el expansionismo continentalista de los norteamericanos seguía vigente, como lo demuestran la Guerra del 98 contra España por la posesión de Cuba, Filipinas y Puerto Rico; el intervencionismo en Colombia, hacia 1903, que terminó con la independencia de Panamá ayudada por los Estados Unidos; e incluso "la ocupación de Nicaragua en 1912” (Franco 48).

Ahora bien, es necesario señalar que los postulados raciales y evolucionistas son posteriores a la Doctrina Monroe (1823). La retórica del Destino Manifiesto también antecede las tesis darwinistas (El origen de las especies es de 1859). No obstante, una porción importante de la propaganda del Destino Manifiesto se basó en la idea de "la superioridad de la raza anglosajona" (cf. Merk 125 y 166). De aquí que en el ensayo de Vasconcelos los "cruces" semióticos -es decir, los significantes que atraviesan un texto y lo significan y resignifican ideológicamente frente a su literalidad - giren sobre todo en torno a los conceptos de "Destino Manifiesto" y "Misión", y no tanto sobre la Doctrina Monroe:

Ella [la raza anglosajona] triunfa porque aduna [i.e.: unifica] sus capacidades prácticas con la visión clara de un gran destino. Conserva presente la intuición de una misión histórica definida, en tanto que nosotros nos perdemos en el laberinto de quimeras verbales. Parece que Dios mismo conduce los pasos del sajonismo, en tanto que nosotros nos matamos por el dogma o nos proclamamos ateos. ¡Cómo deben reír de nuestros desplantes y vanidades latinas estos fuertes constructores de imperios! (Vasconcelos, La raza 13, el énfasis es mío). 
Vasconcelos conocía el sustrato del discurso de la misión norteamericana, esto es, la idea de una "misión histórica" como justificación del expansionismo. No es casual, por tanto, el cruce semiótico, la aparición del significante "misión" en los enunciados de La raza cósmica. La experiencia fronteriza de la infancia de Vasconcelos -cruzaba todos los días el puente "que separaba Piedras Negras de Eagle Pass" para ir a la escuela- no solo le permitió convertirse en bilingüe, sino también adquirir "un marco de referencia dual, por no decir bicultural" (Brading 193).

A este continentalismo norteamericano, Vasconcelos opondrá el continentalismo latinoamericano. En su enunciación murmuran, sobre todo, los ecos de Bolívar y su propuesta de "la patria grande" -esto es, "formar en América la más grande nación del mundo" (Bolívar 78)-. Escribe Vasconcelos: "Bolívar, en parte porque se dio cuenta del peligro en que caíamos, repartidos en nacionalidades aisladas, y también por su don de profecía, formuló aquel plan de federación iberoamericana que ciertos necios todavía hoy discuten" (La raza 15). Este continentalismo asumido en su enunciación es uno de los aspectos más reconocidos del "vasconcelismo". Como señala José Joaquín Blanco, el discurso antiimperialista de Vasconcelos se conjuga con el "continentalismo" latinoamericano. Ambos discursos representan pilares de su proyecto de "una cultura mexicana como un movimiento anticolonialista, bolivariano" (57). La enunciación de Vasconcelos es explícitamente "latinoamericanista" en lo que respecta a su llamado a la unidad de los pueblos con un sustrato cultural común, pero que, sin embargo, han caído en luchas fratricidas con el fin de "[d]ividir, despedazar el sueño de un gran poderío latino" en América (11). Es este el tercer discurso del circuito de interlocución ideológico-político que historiza e ideologiza la enunciación de Vasconcelos.

\section{SÍNTESIS: LA ENUNCIACIÓN ANTIIMPERIALISTA}

Uno de los objetivos principales de la enunciación de Vasconcelos en $L a$ raza cósmica es asumir y definir de manera clara una posición intelectual y cultural respecto al expansionismo simbólico y cultural de los Estados Unidos $^{12}$. Es decir, constituir y configurar un discurso cultural nacional

12 El otro objetivo, estimo, es que este texto operara, performativamente, como “trampolín” para la elección presidencial del año 1929. Elección que, finalmente, no ganó, lo que marcaría su radical giro reaccionario. 
(México) y subcontinental (Latinoamérica) que contrarreste, en el circuito de las "formas culturales", el discurso y la representación simbólica con que Estados Unidos figuró a sus vecinos del sur durante el siglo XIX e inicios del $\mathrm{XX}^{13}$. La enunciación de Vasconcelos, por lo tanto, está signada sobre todo por la urgencia de articular un relato continentalista para hacer frente al imperialismo norteamericano que opera principalmente en el plano discursivocultural. Esta lectura que sostengo se puede advertir en el siguiente párrafo de La raza cósmica:

Cada raza que se levanta necesita constituir su propia filosofía, el deus ex machina de su éxito. Nosotros nos hemos educado bajo la influencia humillante de una filosofia ideada por nuestros enemigos, si se quiere de una manera sincera, pero con el propósito de exaltar sus propios fines y anular los nuestros. De esta suerte nosotros mismos hemos llegado a creer en la inferioridad del mestizo, en la irredención del indio, en la condenación del negro, en la decadencia irreparable del oriental. La rebelión de las armas no fue seguida de la rebelión de las conciencias. Nos rebelamos contra el poder político de España, y no advertimos que, junto con España, caímos en la dominación económica y moral de la raza que ha sido señora del mundo, desde que terminó la grandeza de España. Sacudimos un yugo para caer bajo otro nuevo. El movimiento de desplazamiento de que fuimos víctimas no se hubiese podido evitar aunque lo hubiésemos comprendido a tiempo. Hay cierta fatalidad en el destino de los pueblos, lo mismo que en el destino de los individuos; pero ahora que se inicia una nueva fase de la Historia, se hace necesario reconstituir nuestra ideología y organizar conforme a una nueva doctrina étnica toda nuestra vida continental. Comencemos entonces haciendo vida propia y ciencia propia. Si no se liberta primero el espíritu, jamás lograremos redimir la materia (29-30; el énfasis es mío).

La enunciación de Vasconcelos, la actitud subjetiva que asume en la escritura de este texto, es la "reconstitución" de una ideología, la "nuestra", es decir, la de la "vida continental", tan "mancillada" por el imperialismo político y

13 Un discurso que encontró legitimidad racional en los posteriores postulados evolucionistas del positivismo spenceriano y comteano. De esta relación entre imperialismo norteamericano y positivismo derivó la xenofilia positivista frente a Estados Unidos: "los positivistas, al aceptar como verdadero el darwinismo social, nos ponían de rodillas, decía Vasconcelos, del fetiche justificador de la expansión anglosajona" (Villegas 52). 
cultural de Estados Unidos: "La derrota nos ha traído la confusión de los valores y los conceptos; la diplomacia de los vencedores nos engaña después de vencernos" (7). La enunciación de esta "filosofía" nuestra por parte de Vasconcelos es ideologizada por estos procesos históricos así como por los discursos filosóficos y culturales estudiados. En este sentido, la atención a la enunciación particular de Vasconcelos nos permite comprender de mejor modo su proyecto cósmico, ya que evidencia el lugar y el espacio donde estaba situado el "Ulises criollo". Al igual que hiciera ver Liliana Weinberg respecto a José Martí, el estudio de la enunciación de Vasconcelos permite encontrar "nuevos sentidos" a La raza cósmica "si se la contempla como ligada a la práctica y los circuitos" (120) que él mismo vivió como sujeto histórico.

La especificación del circuito de interlocución de la enunciación vasconceliana amplía y descubre los sentidos del proyecto cósmico. Esta es una aproximación urgente para asir a una de las figuras más trascendentes del siglo XX latinoamericano, pues muchas de sus preocupaciones y motivaciones persisten en nuestro presente: "A diferencia de la mayoría de los ideólogos e intelectuales mexicanos del siglo XX, Vasconcelos no ha sido rebasado por la Historia. Tal vez porque encarna, a un tiempo, la Tradición y su repudio, la esperanza y la desilusión" (Aguilar Rivera 155-56). La ceguera, la oscuridad, el entusiasmo acrítico o la impugnación descontextualizada no revaloran ni esclarecen a Vasconcelos. Si el fuego de su vitalismo abruma o encandila a sus admiradores, las cenizas del águila todavía cubren a sus críticos.

\section{BIBLIOGRAFÍA}

Aguilar Rivera, José Antonio. El fin de la raza cósmica. Consideraciones sobre el esplendor y decadencia del liberalismo en México. México: Océano, 2001.

Basave, Agustín. México mestizo. Análisis del nacionalismo mexicano en torno a la mestizofilia de Andrés Molina Enríquez. 1992. México: Fondo de Cultura Económica, 2002.

Benveniste, Emile. Problemas de lingüística general I. 1966. Trad. Juan Almela. México: Siglo XXI, 2011. 2011.

Blanco, José Joaquín. Se llamaba Vasconcelos. Una evocación crítica. 1977. México: Fondo de Cultura Económica, 1993.

Blenquel, Eduardo. “La Revolución mexicana”, Historia mínima de México. 1973. Ed. Daniel Cosío Villegas. México: El Colegio de México, 1983. 135-154. 
Bolívar, Simón. "Carta de Jamaica". 1815. Para nosotros la patria es América. Caracas: Fundación Biblioteca Ayacucho, 1991. 62-86.

Brading, David. A. Mito y profecía en la historia de México. 1984. Trad. Tomás Segovia. México: Fondo de Cultura Económica, 2013.

Córdova, Arnaldo. La ideología de la Revolución Mexicana. La formación del nuevo régimen. 1973. México: ERA, 2003.

Domínguez Michael, Christopher. Tiros en el concierto. Literatura mexicana del siglo $\mathrm{V}$. 1997. México: ERA, 1999.

Ferrater Mora, José. "Positivismo". Diccionario de filosofía abreviado. Buenos Aires: Sudamericana, 1970. 336-337.

Franco, Jean. "La minoría selecta: Arielismo y Criollismo, 1900-1918”. La cultura moderna en América Latina. 1967. Trad. Sergio Pitol. México: Joaquín Mortiz, 1971. 48-78.

Funes, Patricia. Salvar la nación. Intelectuales, cultura y política en los años veinte latinoamericanos. Buenos Aires: Prometeo Libros, 2006.

Garciadiego, Javier. "El triunfo de Vasconcelos". Relatos e Historias en México 75. Nov. 2014: 38-53.

Henríquez Ureña, Pedro. “Alfonso Reyes”. 1906. Estudios mexicanos. Ed. José Luis Martínez. México: Fondo de Cultura Económica, 2004. 275-283.

Hobsbawm, Erich. Historia del siglo XX. 1914-1991. 1995. Trad. Jordi Ainaud, Carme Castells y Juan Faci. México: Crítica, 2012.

Hozven, Roberto. "Hacia una teoría sobre dos cohesiones simbólicas negativas en el ensayo chileno." Anales de literatura chilena 16 (2011): 155-177.

Krauze, Enrique. Mexicanos eminentes. 1999. México: Tusquets, 2007.

Merk, Frederick. Manifest Destiny and Mission in American History. 1965. Cambridge: Harvard University Press, 1995.

Monsiváis, Carlos. "El ateneo de la juventud”. La cultura mexicana en el siglo XX. Ed. Eugenia Huerta. México: El Colegio de México, 2010. 25-44.

Reyes, Alfonso. "Notas sobre la inteligencia americana”. 1936. Obras completas XI. México: Fondo de Cultura Económica, 1997. 82-91.

Rojas, Rafael. "Retóricas de la raza. Intelectuales mexicanos ante la guerra del 98". Historia Mexicana 49.4 (2000): 593-629.

Said, Edward. Culture and Imperialism. 1993. New York: Vintage Books, 1994.

Todorov, Tzvetan. El miedo a los bárbaros. Más allá del choque de civilizaciones. Trad. Noemí Sabrogués. México: Galaxia Gutenberg, 2013.

"Enunciación". Diccionario enciclopédico de las ciencias del lenguaje. Ducrot, Oswald y Tzvetan Todorov. Trad. E. Pezzoni. Buenos Aires: Siglo XXI Argentina, 1974. 364-368.

Vasconcelos, José. Discursos. 1920-1950. México: Trillas, 2009.

La otra raza cósmica. 1926. Trad. Heriberto Yépez. México: Almadía, 2010.

La raza cósmica. 1925. México: Ed. Porrúa, 2012. 
Villegas, Abelardo. "El Ateneo de la Juventud". El pensamiento mexicano en el siglo XX. México: Fondo de Cultura Económica, 1993. 36-59.

Von Vacano, Diego A. The Color of Citizenship. Race, Modernity and Latin American/Hispanic Political Thought. New York: Oxford University Press, 2011.

Weinberg, Liliana. Situación del ensayo. México: UNAM, 2006. 